\title{
AVALIAÇÃO DO ESTUDANTE: NO EXERCÍCIO DE AVALIAÇÃO DA PRÁTICA PROFISSIONAL
}

\author{
Luzmarina Aparecida Doretto Braccialli ${ }^{1}$ \\ Hélia Sonia Raphael ${ }^{2}$ \\ Mara Quaglio Chirelli ${ }^{3}$ \\ Maria Amélia Campos de Oliveira ${ }^{4}$
}

Recebido: 12/11/07

Aprovado: 20/01/2008

\begin{abstract}
${ }^{1}$ Professora da Faculdade de Medicina de Marília (Famema), doutoranda da Escola de Enfermagem da Universidade de São Paulo (USP),

${ }^{2}$ Professora Doutora da Faculdade de Educação da UNESP, Campus de Marília,

${ }^{3}$ Professora da Famema, Doutora pela USP, Escola de Enfermagem de Ribeirão Preto,

${ }^{4}$ Professora Livre-docente do Departamento de Enfermagem em Saúde Coletiva da Escola de Enfermagem da USP.
\end{abstract}

Resumo: Este estudo aborda a avaliação do exercício da prática profissional (EAPP) no curso de enfermagem da Faculdade de Medicina de Marília (Famema); tem como objetivo analisar a concepção de avaliação do professor que realizou o EAPP com estudantes de primeira a quarta séries do curso. Trata-se de um estudo qualitativo, modalidade análise de conteúdo e identificação da seguinte temática: as ambigüidades do processo de avaliação. Constata-se que a concepção do professor na avaliação no EAPP aproxima-se muito da abordagem de competência dialógica, que articula e integra resultados, atributos e contexto em situações distintas, com diferentes formas de realizar tarefas essenciais para a formação do enfermeiro. Contradições no processo avaliativo entre os professores, porém, estão presentes e necessitam ser constantemente trabalhadas.

Palavras-chaves: Avaliação. Currículo. Ensino. Inovação curricular. Enfermagem.

\section{STUDENT'S EVALUATION: EVALUATING PROFESSIONAL PRACTICE}

Abstract: This paper approached the evaluation of professional practice in the Nursing Program at Marilia Medical School (Famema) with the purpose of analyzing the concept of evaluation of the teacher who used the Professional Practice Evaluation (PPE) with the students of the nursing program. It was a qualitative study which focused on content analysis and the identification of ambiguities in the evaluation process. It was possible to verify that the teacher's evaluation concept of PPE was very close to the dialogic competence approach that articulates and integrates results, attributes and context in distinct situations with different ways of carrying out essential tasks in the nurse's education. However, there are contradictions about evaluation among teachers and these contradictions must be constantly revised.

Key-words: Evaluation. Curriculum. Curricular innovation. Teaching nursing.

\section{Introdução}

A Faculdade de Medicina de Marília (Famema) é criada em 1966, como Instituição Pública Municipal de Ensino Superior de Marília, com o curso de Medicina e posteriormente com o de Enfermagem em 1981. Atualmente, após um processo de estadualização concluído em 1995, é uma autarquia do Governo do Estado de Sâo Paulo, ligada à Secretaria de Ensino Superior. 
Em 1997, a Famema a dá início a um processo de mudança curricular, tendo como finalidade a formação de médicos e enfermeiros com visão crítica, reflexiva e humanista, em sintonia com a implementação das Diretrizes Curriculares Nacionais para a formação de profissionais nas duas carreiras. A partir de 2003, adota um currículo integrado e orientado por competência dialógica, optando por dar continuidade na aplicação do Método da Aprendizagem Baseada em Problemas (ABP), na Unidade Educacional Sistematizada (UES) e do Método da Problematização, na Unidade de Prática Profissional (UPP).

A adoção de um método de ensino-aprendizagem crítico e reflexivo assume coerência com a organização curricular por competência dialógica e com o currículo integrado na medida em que estão ancorados na articulação teoriaprática, na formação a partir do mundo do trabalho, buscando refletir acerca da prática profissional em saúde, tendo como perspectiva a sua transformação.

A proposta de formação de profissionais de saúde da área de Enfermagem e Medicina da Famema é uma das possibilidades de projeto político-pedagógico que favorece a aproximação entre as instituições formadoras e os serviços do SUS, como uma resposta às políticas do Ministério da Saúde para a formação de recursos humanos em saúde.

A partir de 2002, com a mudança do Governo Federal, o Ministério da Saúde procura impulsionar mais fortemente mudanças na formação inicial (graduação) dos profissionais de saúde, instituindo a "Política de educação e desenvolvimento para o SUS: caminhos para a educação permanente” (BRASIL, 2004). Até então, os programas de incentivo às mudanças na formação, tais como o PIT (Programa de Interiorização do Trabalho) e o PROFAE (Projeto de Profissionalização dos Trabalhadores da Área de Enfermagem), estavam voltados para a fase após a graduação. Além disso, a expansão do projeto Saúde da Família contribua com a estratégia de mudança do modelo de atenção à saúde.

De sua parte, o Ministério da Educação, considerando as Diretrizes Curriculares Nacionais, a partir de 2002, passa a apoiar a elaboração de projetos de mudanças nos cursos de Medicina, por meio do Promed em 2003 e de Enfermagem e Odontologia, por meio do Pró-Saúde em 2005. Esses projetos trazem recursos políticos, financeiros e estratégicos para processos de mudança na formação inicial dos profissionais, em articulação com os serviços de saúde.

A Famema foi contemplada pelo Promed, em 2003, com o projeto intitulado "Famema Século XXI", realizado em parceria com a Secretaria Municipal de Saúde (SMS), e com o Pró-Saúde, em 2005, em continuidade ao projeto em curso, com a inclusão da enfermagem (FACULDADE DE MEDICINA DE MARÍLIA, 2003; FACULDADE DE MEDICINA DE MARÍLIA; 2005). 
Em conseqüência, os currículos dos Cursos da Famema passam a utilizar o referencial da competência profissional, desenvolvendo em conjunto os desempenhos considerados comuns às duas carreiras, além da organização curricular integrada.

Um currículo integrado caracteriza-se pela efetiva articulação do ensino e da prática profissional, no avanço da construção de teorias e na busca de soluções específicas para diferentes situações adaptadas à realidade local e aos padrões culturais próprios de uma determinada estrutura social (DAVINE, 1989). No currículo integrado, considera-se também que a educação parte do mundo do trabalho. Em vista disso, busca-se realizar uma reflexão sobre a prática profissional, tendo como objetivo articular a formação ao trabalho, construindo significado ao fazer do enfermeiro.

A reorientação da formação dos profissionais de saúde em um modelo que busca estimular a capacidade reflexiva, a agilidade para atuar na incerteza, articulando teoria e prática e buscando a superação de uma abordagem fragmentada na abordagem dos problemas de saúde, apresenta conflitos com a matriz flexneriana ${ }^{1}$ e a metodologia tradicional de ensino, as quais vêm norteando os currículos da área de saúde.

Santomé (1998) considera que a aplicação do modelo por disciplinas tem produzido currículos geralmente baseados no modelo linear, ou seja, um conjunto de disciplinas justapostas em quebra-cabeças que os estudantes não conseguem montar, por abordarem os conteúdos descolados da realidade, sem apresentar os conflitos e contradições contidas nela e muitas vezes sem significado para a formação.

No currículo linear aprende-se, de forma muitas vezes inconsciente, a identificar os problemas na realidade, como também os critérios de estabelecimento de verdade e validade, pois a análise do que existe na realidade por meio dos métodos, técnicas e pensamentos próprios de cada disciplina como uma forma de organização do conhecimento, de ler e interpretar o mundo não é estudada criticamente, sendo valorizado o domínio das matérias de forma isolada.

O resultado dessa proposta curricular tem sido a incompreensão daquilo que é estudado à força, por coerção mais ou menos manifesta, pois a fragmentação dos conhecimentos causa dificuldade

\footnotetext{
1 No início do século XX, após ampla pesquisa sobre a educação médica americana, foi elaborado o Relatório Flexner, no qual se recomenda a criação de departamentos, a individualização e desenvolvimento crescente do ensino e pesquisas no âmbito das ciências básicas e a criação de hospitais-escola como campo fundamental do treinamento clínico. A escola de medicina deveria fazer parte de uma universidade e formar um corpo docente permanente dedicado ao ensino e à pesquisa. Este relatório contribuiu para que a educação médica centrasse o conhecimento nas ciências biológicas, tornando-se mais especializada e centrada nos hospitais.
} 
para compreender o que foi estudado/memorizado (SANTOMÉ, 1998, p.104).

Tal conhecimento é acadêmico e a realidade cotidiana aparece desfigurada, descontextualizada e com informações aparentemente sem qualquer ideologia. $\mathrm{O}$ estudante acaba tendo como finalidade somente superar as barreiras necessárias para passar de ano ou para a etapa posterior.

A promessa inerente a um modelo curricular integrado é a de conectar o estudante à vida cotidiana, no caso os serviços de saúde e a comunidade e, a partir das experiências vividas num determinado cenário de ensino-aprendizagem, procurar entender e ampliar, por meio de sucessivas aproximações, a compreensão sobre o que está ocorrendo e o que ele pode fazer com os problemas identificados, como pode intervir numa dada realidade enquanto profissional da enfermagem.

Por outro lado, a orientação curricular por competência requer uma opção de base teórico-filosófica quanto ao conceito de competência que, segundo Ramos (2001), pode ser resumido em três tendências principais: o condutivismo/funcionalismo, o construtivismo francês e o modelo australiano.

No referencial condutivista, há uma adaptação da formação para o mercado de trabalho; interesse no produto ou resultado como expressão de eficiência; o referencial pedagógico adota a estrutura comportamentalista, tendo como referência a psicologia de Skiner e Bloom; busca "o fazer bem feito," ter habilidade na tarefa; estimulando a competitividade e a competência. Seguindo a mesma tendência, o funcionalismo ressalta os resultados e os produtos em detrimento do processo, não enfocando com relevância os atributos que fundamentam as práticas do trabalho; tem uma relação direta com a função e as tarefas e descreve a competência como uma lista de conhecimentos e de tarefas sem articulação.

Ancorado no construtivismo, o modelo francês descreve a competência como uma lista de atividades; o referencial está voltado para a construção social da competência; utiliza o conceito de competência no singular quando faz referência a mudanças na organização do trabalho e, no plural, para designar mudanças no conteúdo; vincula trabalho e educação e relaciona as atividades profissionais aos diferentes saberes, sendo eles: saber, saber ser, saber fazer, saber conviver, no sentido de "ser capaz de".

Por fim, o modelo australiano, também embasado no construtivismo, apresenta aproximação com a escola crítica: o conceito de competência apresenta-se como uma combinação de atributos em situação prática; utiliza o conceito no 
singular ao fazer referência à prática profissional; utiliza o desempenho (capacidades em ação) e padrões de competência como dimensão; busca a integração, o diálogo entre a teoria e a prática, considerando o contexto e a cultura do local de trabalho e também os valores e a ética.

Ao optar pela construção da formação a partir do mundo do trabalho, conforme apontado anteriormente, adota-se o referencial australiano que propõe o diálogo da formação entre o mercado de trabalho e a universidade, articulando a teoria e a prática. Com esse referencial de competência espera-se que o estudante mobilize/construa seu desempenho na ação, de forma pertinente e no momento oportuno, para solucionar problemas e necessidades de saúde nos cenários de ensino-aprendizagem em que se encontra.

Roldão (2005) destaca que a capacidade de mobilização e de convocação dos atributos necessários para atuar face a uma situação, articulando-os de forma pertinente e oportuna, seria a própria essência da competência. Portanto, não estamos falando somente de aplicação de recursos, mas da mobilização de atributos frente a uma dada situação da prática profissional, de acordo com o grau de autonomia e domínio do estudante no momento de sua formação.

Entende-se por competência a capacidade de articular e mobilizar conhecimentos, habilidades e atitudes, colocando-os em ação para resolver problemas e enfrentar situações de imprevisibilidade em uma dada situação concreta de trabalho e em um determinado contexto cultural (ZARIFIAN, 1996).

Perrenoud (1999) define competência como a "capacidade de mobilizar um conjunto de recursos cognitivos (saberes, capacidades, informações, etc.) para solucionar, com pertinência e eficácia, uma série de situações”. Considera também que a competência é transversal, ou seja, acompanha o sujeito da aprendizagem nas diversas situações vividas durante a formação.

\section{O Processo de Avaliação no Currículo Integrado e Orientado por Competência}

Ao se adotar um currículo por competência, há necessidade de mudanças nos processos de ensino-aprendizagem e também na avaliação do funcionamento das instituições, das classes, do papel do professor e do estudante.

Do ponto de vista educacional, em um currículo orientado para a construção de competência, a aprendizagem se dá a partir do mundo do trabalho, no confronto com situações reais da prática profissional, baseada na aprendizagem significativa. Esse currículo deve contemplar mudanças na formação profissional, que abrangem desde distinta seleção de conteúdos/tarefas, até expressivas 
inovações nos processos de ensino aprendizagem e, conseqüentemente, no processo avaliativo.

O processo avaliativo, num currículo integrado orientado por competência, tem importância na medida em que proporciona a reflexão sobre o processo ensino-aprendizagem, identificando as fragilidades e as potencialidades, apontando para sua reconstrução.

A avaliação deve ser um ato dinâmico, de natureza processual, que favorece o processo de ensino-aprendizagem. Na avaliação participativa, professor e estudante comprometem-se com a construção do conhecimento e com a formação de um profissional competente (FACULDADE DE MEDICINA DE MARÍLIA, 2005).

Assim sendo, a avaliação é uma das atividades mais significativas e norteadoras do processo ensino-aprendizagem, é contínua, repleta de contradições e se dá dentro e fora da escola, formal e informalmente (DESPREBITERIS, 1989).

Avaliar é emitir juízo de valor e, por isso, envolve sempre uma apreciação subjetiva que, ao invés de ser negada, deve ser controlada e bem utilizada. Para tanto, as informações válidas necessitam ser obtidas de diversas fontes e em diferentes situações. Os critérios utilizados devem ser democraticamente discutidos para que sejam validados e devem ser capazes de revelar evidências que permitam analisar processos e produtos, orientando a tomada de decisões para verificação do grau de alcance dos desempenhos previamente estabelecidos e o aperfeiçoamento contínuo do processo ensino-aprendizagem.

De acordo com Perrenoud (1999), podem-se identificar duas lógicas na avaliação: a lógica formativa e a lógica somativa ou certificativa. A avaliação na lógica formativa é compreendida como fonte de regulação dos processos de aprendizagem, ou seja, sua vocação é contribuir para as aprendizagens, pois permite a intervenção deliberada do professor, induzindo a uma regulação antecipada de uma aprendizagem em curso; e na lógica somativa ou certificativa sua função é fazer um balanço das aquisições do estudante e decidir por sua aprovação ou não para etapas subseqüentes do programa de ensino.

A princípio contraditórias, ambas as lógicas podem coexistir, segundo o autor, se a escola "[...] evolui para pedagogias diferenciadas, percursos individualizados, o trabalho por situações problema e o desenvolvimento de competências" (PERRENOUD, 1999, p.168). No entanto: não pode ser suprimida por mágica, mas será tanto mais suportável 
quanto mais se desenvolver uma pedagogia diferenciada eficiente. O mecanismo prioritário não é suprimir toda avaliação somativa ou certificativa, mas criar condições de aprendizagem mais favoráveis para todos e inicialmente para os mais necessitados (PERRENOUD, 1999, p. 165).

O caráter formativo da avaliação é representado pelas oportunidades de recuperação (plano de recuperação elaborado a partir das dificuldades apresentadas pelo estudante e identificadas pelo professores). $\mathrm{O}$ caráter somativo expressa-se na obrigatoriedade de realização das atividades avaliativas e, ainda, ao final das oportunidades de recuperação, quando a lógica somativa é aplicada com o propósito de análise da progressão de estudante, ao longo das unidades educacionais e séries.

A avaliação formativa tem sido pensada para múltiplos usos, sendo fundamental para quem ensina e para quem aprende, servindo tanto para reforçar determinada situação, quanto para corrigir erros, falhas ou distorções. Serve também como contrapeso da avaliação somativa "inevitável, tantas vezes, dadas às necessidades institucionais, evitando de algum modo certo efeito perverso que esta avaliação comporta" (ABRECHT, 1994, p. 35).

Tradicionalmente, a avaliação escolar sempre foi vista como um momento de grande estresse, porque sua finalidade era apenas classificar os alunos, atribuindo-lhes notas ou conceitos. Na perspectiva de um currículo integrado, orientado por competência, proposto pelo Curso de Enfermagem da Famema, a avaliação ocupa outro espaço em que as contradições devem ser explicitadas, proporcionando reflexão e a transformação da prática profissional.

Com a perspectiva de realizar um currículo orientado por competências, com atividades de ensino aprendizagem articuladas e integradas ao cenário de prática, buscando a identificação de necessidades de saúde, com cuidado efetivo e integral à pessoa, sendo essa não um mero objeto para o desenvolvimento de capacidades e sim uma relação com vínculo e responsabilização, tal como ocorre na vida real. As duas primeiras séries dos Cursos de Enfermagem são integradas ao Curso de Medicina e se constituem em Unidades Educacionais: Unidade de Prática Profissional (UPP), Unidade Educacional Sistematizada (UES) e Laboratório de Prática Profissional (LPP).

Nessa lógica, o processo de ensino-aprendizagem fundamenta-se nos pressupostos da aprendizagem significativa e a prática é entendida como o eixo que estrutura a construção coletiva do conhecimento - é o aprender fazendo. Essa é uma pedagogia individualizada, uma vez que a construção de significado envolve a problematização dos conteúdos prévios já assimilados e a explora- 
ção dos valores sócio-culturais construídos ao longo da vida, requerendo uma abordagem particular e um tempo específico para cada estudante, a fim de que esse construa novos significados para o desenvolvimento de capacidades para o trabalho em saúde, o reconhecimento das próprias dificuldades e a elaboração de propostas de superação dessas. As atividades educativas favorecem essa construção na medida em que, partindo de ações mais livres, que consideram as capacidades prévias dos estudantes (construindo desta forma uma linha de base do grupo), para ações educativas mais instrumentalizadoras que permitam a aplicação, com excelência, dos métodos clínico e epidemiológico para o trabalho em saúde.

Nas quatro séries do curso são utilizadas estratégias de ensino aprendizagem que se constituem em eixos de atividades educacionais, sendo o Ciclo Pedagógico composto por cinco momentos: 1) confronto experiencial - realizado a partir da observação/realização de tarefas da prática profissional que, permitindo exposição e exploração dos valores, procura explorar os conhecimentos e destrezas que cada estudante já possui; 2) elaboração de síntese provisória e levantamento de questões de aprendizagem; 3) busca e análise de informações e fontes; 4) elaboração de nova síntese 5) avaliação individual, grupal e do ciclo. (FACULDADE DE MEDICINA DE MARILIA, 2007).

Esses momentos do ciclo proporcionam reflexão e análise da situação vivenciada e certamente possibilitarão a construção de novas capacidades que serão alcançadas em futuras situações práticas.

A terceira série do Curso de Enfermagem caracteriza-se pela introdução dos estudantes na unidade hospitalar e estrutura-se em uma unidade educacional: Unidade de Prática Profissional 3 (UPP3) - o cuidado ao indivíduo hospitalizado que desenvolve a área de competência do cuidado às necessidades individuais de saúde, em todas as fases do ciclo de vida, em diferentes contextos no cenário hospitalar.

A quarta série do Curso de Enfermagem caracteriza-se pela continuidade dos estudantes na Unidade Hospitalar e no Programa Saúde da Família da Rede Básica dos Serviços de Saúde e estrutura-se em uma Unidade Educacional: Unidade de Prática Profissional 4 (UPP4). Contempla as áreas de cuidado à saúde das pessoas, famílias e comunidade na perspectiva do modelo de vigilância à saúde em todas as fases do ciclo da vida, gestão e organização do processo do trabalho em saúde (FACULDADE DE MEDICINA DE MARILIA, 2007).

Além das unidades descritas, da segunda à quarta série o estudante participa de uma Unidade Educacional Eletiva e elabora um Trabalho de Conclusão de Curso (TCC) que lhe possibilita suprir suas necessidades educacionais. 
Os estudantes constroem durante todo o processo o seu portfólio, sendo esse individual, narrativo e reflexivo. Eles estruturam e fundamentam a construção de seu próprio conhecimento num processo contínuo. As narrativas no portfólio são registradas seguindo os momentos do processo de ensino-aprendizagem.

O cenário simulado da prática profissional é desenvolvido em um laboratório de prática profissional (LPP), destinado a ser um momento sistematizado da aprendizagem cujas atividades, previamente estruturadas pelos docentes na forma de situações planejadas, estão muito próximas de situações vivenciadas pelos estudantes no cenário real de atenção básica e hospitalar. Nessas situações, os pacientes são simulados para que os estudantes possam desenvolver capacidades e habilidades que permitam vivenciar a ocorrência de erros inerentes ao processo ensino-aprendizagem apresentados em cenário real e simulado.

O LPP tem como diretriz utilizar as situações que, no momento de avaliação, guardam relação com os desempenhos esperados e desenvolvidos na unidade de prática profissional (UPP) e com as situações exploradas nas unidades sistematizadas (UES). As atividades do LPP são realizadas em dois momentos. No primeiro encontro, o estudante realiza atendimento do paciente simulado com a observação de professores (semiologia, comunicação e professor da UPP), que anotam os pontos que requerem atenção (momento avaliação) e prescrevem o que deverá ser trabalhado no próximo encontro (momento apoio).

Essas situações simuladas são realizadas no decorrer do ano e ao término do ano letivo. Trata-se de um momento formal de cada série, caracterizado como um exercício de avaliação da prática profissional (EAPP). Essa avaliação nas duas primeiras séries do Curso de Enfermagem tem caráter formativo e somativo (a sua participação no exercício); na terceira e quarta séries, caráter formativo e somativo (sua certificação profissional).

O EAPP constitui uma atividade nova para o Curso de Enfermagem da Famema pelo caráter formativo e somativo, com verificações de processo contínuas e sistemáticas de tal forma que o desenvolvimento individual possa ser monitorado e o planejamento e programação de atividades educativas adaptados às suas necessidades. $\mathrm{O}$ estudante tem autonomia e domínio crescentes nas séries e, dentro dessas, cabe ao professor ser o facilitador e estimulador dessas conquistas e do crescimento pessoal e profissional dos estudantes.

A avaliação do estudante é referenciada em critérios. Isso significa que um padrão, considerado apropriado, é utilizado para comparação com os desempenhos de cada estudante, ao longo do curso. Essa avaliação critério-referenciada permite que o estudante conheça o desempenho considerado satisfatório, orientando sua aprendizagem. Em vista disso, faz-se necessário avaliar como está 
se dando o processo avaliativo do EAPP pelos professores durante as séries do Curso de Enfermagem da Famema, já que esse tem sido um processo repleto de contradições. Objetivo: analisar a concepção de avaliação do professor que realiza o EAPP no curso de Enfermagem da Famema.

\section{Método}

Baseando-se na abordagem de amostra intencional, em que se consideraram as avaliações transcritas qualitativamente do EAPP realizado no ano de 2006, foram selecionados, dos quatro anos do curso de enfermagem, formatos preenchidos pelos professores de cada série e que avaliaram os estudantes com o conceito satisfatório e outros que os avaliaram de maneira insatisfatória ao final do campo do formato. Assim, do total de 157 formatos preenchidos pelos facilitadores da UPP (podendo ser docentes do curso de Enfermagem e Medicina da Famema, professores colaboradores, sendo esses enfermeiros e médicos assistenciais da rede pública e hospitalar da rede básica de saúde e da rede hospitalar de Marília), foram selecionados 20 formatos para análise.

Por esses formatos, foi analisado, nas quatro séries, o desempenho individual de necessidades de saúde, contemplando as tarefas, história e o exame clínico, a formulação de problemas, a elaboração do plano de cuidados e os comentários finais dos facilitadores e do estudante. $\mathrm{Na} 3^{\mathrm{a}}$ e $4^{\mathrm{a}}$ séries, os desempenhos foram selecionados satisfatoriamente e insatisfatoriamente por áreas específicas. $\mathrm{Na}$ $3^{\text {a }}$, tratou-se de cuidado ao adulto hospitalizado, cuidado à criança hospitalizada e cuidado à mulher em situações obstétricas hospitalizada, contemplando-se as mesmas tarefas e atributos descritos na $1^{\mathrm{a}}$ e $2^{\mathrm{a}}$ séries. $\mathrm{Na} 4^{\mathrm{a}}$ série, a amostra se limitou aos instrumentos considerados satisfatórios no cuidado individual, coletivo e gestão, por não haver na avaliação dos professores nenhum estudante insatisfatório. No cuidado individual, os atributos foram os mesmos. Quanto ao cuidado coletivo, analisou-se a identificação de necessidades de saúde, o inquérito populacional e investigação epidemiológica, a formulação dos problemas/diagnóstico situacional, a elaboração, execução e avaliação do plano de cuidado, comentários finais e/ou aspectos que requerem atenção e os comentários do estudante. No cuidado à gestão, a organização, a elaboração e o planejamento do processo de trabalho junto à equipe e a avaliação do trabalho em saúde.

A metodologia utilizada para a análise dos formatos baseou-se na análise de conteúdo, modalidade temática, com ênfase na abordagem qualitativa de pesquisa social (BARDIN, 1995; MINAYO, 1994 e GOMES, 2002). 
A técnica de análise temática "consiste em descobrir os 'núcleos de sentido' que compõem a comunicação e cuja presença ou freqüência de aparição podem significar alguma coisa para o objetivo analítico escolhido" (BARDIN, 1995).

Inicialmente foi realizada uma leitura de cada instrumento selecionado, buscando a compreensão global de cada avaliador, em que não só se privilegiou o conteúdo, como também a sua lógica. Em seguida, pelos confrontos de diferentes instrumentos analisados, buscou-se identificar núcleos de sentido ou eixos que estruturavam os depoimentos, em torno dos quais se agrupavam características comuns (GOMES, 2002). Após essa etapa, os dados foram discutidos.

Para garantir o sigilo dos depoimentos que apoiaram as análises realizadas, os participantes foram identificados, segundo os anos do curso de enfermagem $\left(1^{\circ}, 2^{\circ}, 3^{\circ}\right.$ e $\left.4^{\circ}\right)$ e os responsáveis pelo preenchimento dos formatos, como o enfermeiro docente (ED), médico docente (MD), professor colaborador enfermeiro assistencial da rede (ER), professor colaborador enfermeiro assistencial da unidade hospitalar (EH), professor colaborador médico assistencial da rede (MR), professor colaborador médico da unidade hospitalar (MH).

\section{Análise dos Resultados}

Foi possível constatar que, de uma forma geral, o Exercício de Avaliação da Prática Profissional (EAPP) está constituído no Curso de Enfermagem da Famema como um processo avaliativo formativo e somativo, sendo implementado pelos docentes médicos/enfermeiros da instituição e professores colaboradores médicos/enfermeiros da Famema e da Rede Municipal de Saúde.

Os participantes do processo, sendo um desses um estudante, consideraram "esse momento como sendo privilegiado para a sua formação" (ED, MR, 1 $\left.{ }^{\mathrm{a} S}\right)$. Percebe-se que o EAPP propicia a revisão das contradições da aprendizagem durante a construção dos desempenhos e a possibilidade de corrigi-los no seu processo de formação.

Mesmo acontecendo em um cenário simulado e num momento formal de avaliação, trata-se de um desafio estratégico de avaliação desde o início da formação do futuro profissional. O EAPP também possibilita ao professor rever sua concepção de avaliação e como está trabalhando a prática de avaliação em seu cotidiano.

$\mathrm{Na}$ análise do formato 5, que trata do preenchimento, pelos professores da Famema, da avaliação do desempenho de cada estudante em relação à sua prática profissional em processo, identifica-se a seguinte temática: as ambigüidades do processo de avaliação. 


\section{As ambigüidades do processo de avaliação}

Pode-se observar que o significado da avaliação ainda é conflitante e divergente entre aqueles que participam da formação do estudante. Existe disparidade de ação entre os responsáveis por essa tarefa, revelando a diversidade de entendimentos da proposta pedagógica. Nessa construção coletiva, os professores são permeados por histórias de vida distintas e em tempos diferentes, com concepções que se aproximam ou se distanciam da proposta do processo avaliativo institucional.

Em alguns momentos, percebe-se que o estudante não tem conseguido mobilizar seus atributos de forma combinada no momento da avaliação no EAPP, sendo reconhecido pelo avaliador que "o seu desempenho no dia a dia foi muitas vezes melhor que o apresentado nessa avaliação" (ED, MR, $\left.1^{\mathrm{a} I}\right)$.

Nessa perspectiva, o EAPP pode ser visto como um dos momentos do processo de avaliação, enquanto acompanhamento do estudante, e uma das referências de parâmetro da aprendizagem construída até o momento. Possibilita ao estudante a identificação de suas fortalezas e suas fragilidades na ação profissional, com o propósito de subsidiar decisões futuras, entendendo que isso implica postura de vida inerente à profissão.

A avaliação "envolve um ato que ultrapassa a obtenção da configuração do objeto, exigindo o que fazer ante ou com ele" (LUCKESI; CIPRIANO, 1996, p.76). O que a maioria das escolas faz é trabalhar com a verificação e classificação das pessoas e não com a construção da aprendizagem. A Famema, entretanto, assumiu a responsabilidade de acompanhar o desempenho do estudante nos seus diversos momentos de vivência nos cenários reais e simulados da prática profissional, proposta documentada no Projeto Político-Pedagógico do Curso de Enfermagem.

Nesse caso, a avaliação deve ser um processo interacionista, negociada e responsiva, entre o professor e o estudante, "ela se situa e se desenvolve a partir de preocupações, proposições ou controvérsias em relação ao objeto da avaliação, seja de um programa, projeto, curso ou outro foco de atenção" (PENNA FIRME, 1994, p. 111). Os sujeitos estão, pois, inseridos numa dada situação, num contexto, que interfere na elaboração da sua aprendizagem e cada um, ou seja, o professor e o estudante necessitam da reflexão acerca de sua prática cotidiana para reconstruir o processo de conhecimento.

Na avaliação formativa, considera-se a qualidade do ensino e da aprendizagem. Esse termo foi utilizado por Scriven em 1967 e, a partir de então, vários educadores adotaram a avaliação formativa com o propósito de acompanhar o estudante na sua progressão no processo de aprendizagem. 
Em contrapartida, a avaliação somativa não tem como finalidade comparar estudantes das mesmas séries ou de outras, e sim ter uma avaliação sistemática do processo de cada estudante, como sendo único, com seus mecanismos de aprendizagem, tendo o professor como um mediador desse processo e reduzindo os efeitos negativos da avaliação.

Esses momentos de ação e reflexão na avaliação formativa permeiam os quatro anos do curso de Enfermagem entre os professores e estudantes. Percebeu-se, que nas séries iniciais, a área de competência "avaliação do estado de saúde individual" se fez presente com ênfase nas tarefas "realiza história clínica e exame geral", porém alguns docentes sinalizaram a importância de um exame físico específico "perfeito" na $2^{\mathrm{a}}$ série, esquecendo-se de que a aprendizagem desses se dará ao longo dos quatro anos de formação, assim também reforçaram a necessidade de o estudante elaborar diagnóstico sindrômico. Pontuaram, ainda, que o levantamento das necessidades de saúde e o plano de intervenção ainda apresentam fragilidades e necessitam ser trabalhados no decorrer dos próximos anos.

Percebe-se que tem havido contradições das concepções de avaliação, com relação ao que se propõe no projeto. Considera-se que o estudante estará apto para progredir para outra série somente se ele já estiver desenvolvendo de forma completa as tarefas do cuidado individual e reforça-se a importância de aprofundar o conhecimento, a habilidade e até mesmo as atitudes nessas tarefas nas séries iniciais do curso.

Outros avaliadores consideraram, porém, que o estudante poderá se desenvolver durante as séries seguintes, tendo outras oportunidades de viver situações em que ele possa aprender a mobilizar os seus atributos, identificando os seus problemas e as necessidades de aprendizagem.

Outro ponto identificado pelo professor como positivo foi a preocupação do estudante, desde o início do curso, com as questões éticas e as medidas de biossegurança. O professor identifica que o "estudante é cuidadoso, preocupase em pedir o consentimento para a realização do exame físico (ED, EH, $3^{\mathrm{a}} \mathrm{S}$ ), tem a preocupação com a questão ética e com as medidas de biossegurança" (MD, ER, $\left.1^{\mathrm{a}} \mathrm{S}\right)$.

Outra dificuldade encontrada e destacada pelos avaliadores envolve a comunicação verbal e não verbal, que não estariam adequadas para a situação simulada. Não teceram, porém, comentário e recomendações no campo específico do formato para essa tarefa. Isso pode demonstrar que o impresso não está sendo preenchido adequadamente, e/ou que os docentes não estão entendendo o próprio processo de avaliação. 
Por outro lado, há também discordância dos critérios de avaliação, pelo fato de os professores registrarem, em forma de texto em todos ou em alguns dos campos do formato, que o "estudante consegue desempenhar os procedimentos propostos para o momento" (MD, ER, $\left.1^{\text {a }} \mathrm{S}\right)$ ou inadequadamente, mas com o conceito satisfatório no campo correspondente. Outra situação aponta que não ter havido nenhum registro qualitativo do desempenho, mas o conceito foi insatisfatório.

Por fim, ocorreram situações em que, ao aparecerem ações com desempenho inadequado, não houve o registro de recomendação pelos avaliadores. Observou-se também que o "estudante não utilizou, na maioria das vezes, seu campo de avaliação para se manifestar a respeito das considerações realizadas pelo professor" (ED, MR, 1 $\left.{ }^{\mathrm{a}} \mathrm{I}\right)$.

No caso de o estudante utilizar o seu campo de comentários no formato de avaliação, percebeu-se que o processo de avaliação possibilita ao estudante uma reflexão sobre sua atuação e o quanto ela pode ter sido prejudicada por outros determinantes. Uma estudante referiu "fiquei nervosa para realizar o EAPP e isso atrapalhou minha avaliação e não consegui diminuir o nervosismo antes de atender o paciente" (ED, EH, $\left.3^{\mathrm{a}} \mathrm{I}\right)$.

Somente a partir de uma concepção de avaliação mais ampliada e incorporada pelo professor, é possível tecer comentário, construir uma relação de confiança para mostrar ao estudante o quanto ele já conseguiu desenvolver do seu conhecimento e habilidade e o quanto um momento de estresse interferiu na sua postura com o paciente. O professor refere que "é muito bom perceber que o estudante tem uma noção bem clara da amplitude dos elementos que precisam ser coletados e dos exames a serem realizados, mas o seu nervosismo nesse momento prejudicou o seu contato com a paciente" (ED, MR, $1^{\mathrm{a} I}$ ).

Segundo Perrenoud $(1999$, p. 149) “... avaliação formativa coloca à disposição do professor informações mais precisas, mais qualitativas, sobre os processos de aprendizagem, as atitudes e as aquisições dos alunos".

Também foi possível identificar a avaliação como uma relação de troca e o quanto essa proporciona ao estudante rever os pontos que ainda precisam ser aprofundados. Como a auto-avaliação se faz necessária desde o início do curso, trata-se de uma cultura quase impossível para o estudante não acostumado com essa prática em sua vida acadêmica. Alguns estudantes, mesmo sendo insatisfatórios, reconhecem o momento formativo para sua profissão, “.... concorda com a avaliação feita, não sente essa como uma punição, reconhece os pontos de fragilidade e se propõe a trabalhar nesses. É possível sentir uma relação mais horizontal, onde a troca é fundamental" (ER, MD, 1ª). 
No entanto, outros estudantes "não se identificam com a avaliação realizada pelo professor" (ED, EH, $\left.3^{\mathrm{a}} \mathrm{I}\right)$. Isso demonstra mais uma vez que a mudança da concepção de avaliação se dá em processo de construção institucional das pessoas e não somente pela apresentação de regras regimentais. Segundo Perrenoud (1999, p. 09),

"avaliar é também privilegiar um modo de estar em aula e no mundo, valorizar formas e normas de excelência, definir um aluno modelo, aplicado e dócil para uns, imaginativo e autônomo para outros... Como, dentro dessa problemática, sonhar com um consenso sobre a forma ou o conteúdo dos exames ou da avaliação contínua praticada em aula?".

Outra fragilidade apontada é a fragmentação das dimensões para a realização do cuidado. Nas primeiras séries, o estudante "se limitou a uma dimensão, sendo essa a psicológica, tendo dificuldade de contemplar todas as dimensões na exploração do contexto de vida" (MD, ER, 1ª), ou seja, não há entendimento das três dimensões biológica, psicológica e social.

Outra questão que aparece como dificultador para a realização das tarefas é "a adequação do tempo e a valorização de uma dimensão em relação às outras" (ED, MR, $\left.2^{\mathrm{a}} \mathrm{S}\right)$. O estudante apresenta inseguro para distribuir o tempo e muitas vezes ultrapassa o limite e gasta um tempo muito maior do que o esperado, o que reforça a necessidade de se ter mais habilidade na tarefa proposta. Isso tem ocorrido com maior freqüência nas séries iniciais do curso e diminuído na última série do curso.

Percebe-se que, nas primeiras séries, os desempenhos da área de competência do cuidado coletivo e da área de gestão e organização dos serviços de saúde não foram explorados de forma abrangente. Durante a realização do EAPP na primeira série, "o desempenho de gestão que seria o envolvimento da equipe na realização do cuidado individual aparece de forma apropriada para o momento" (ER, MD, $1{ }^{\text {aaS }}$ ). Porém, essa ação foi explorada de forma pontual e não enquanto uma área de competência a ser desenvolvida.

Já na última série é dada uma atenção especial para esses desempenhos, que são avaliados em estações separadas, o que não acontece nas séries anteriores. O professor avaliador observa que "não é possível comparar o desempenho do coletivo e gestão com séries anteriores, por ser um desempenho construído unicamente nessa série" (ER, ED, 4a S).

Dessa forma, o fato que chamou a atenção do professor é que somente na última série do curso aparece claramente no EAPP a utilização do raciocínio 
clínico, epidemiológico e o uso das ferramentas do planejamento estratégico. O professor identifica, então, a articulação que o estudante é capaz de fazer nessa série, pois "elabora plano de cuidados no coletivo, utiliza ferramentas do planejamento estratégico em saúde, desenvolve um raciocínio amplo com a noção de gestão, valoriza e sente a importância da participação da equipe de saúde. Também reforça a articulação de diferentes níveis de atenção e reforça o uso de evidências científicas nesse campo" (ED, EH, $\left.4^{\mathrm{a}} \mathrm{S}\right)$.

Portanto, mesmo sendo a última série do curso, "certificar competência permanece uma atividade desafiadora por causa da complexidade da avaliação e do impacto que produz tanto para profissionais egressos, instituições formadoras, docentes e processos de ensinoaprendizagem, quanto para a própria sociedade e, principalmente, para os pacientes (LIMA, 2004, p.127).

\section{Considerações Finais}

A avaliação no EAPP do curso de Enfermagem da Famema, realizada pelo professor, contribui para a melhoria do processo ensino aprendizagem, embora seja possível constatar que tanto o professor quanto o estudante precisam compreender mais claramente que o espaço do instrumento de avaliação (formato) a ser usado tem importância para a transformação do processo, pois o que se espera são profissionais críticos, reflexivos, que atuem na integralidade.

Por estarmos em constante aprendizagem, há necessidade urgente de uniformidade e entendimento da proposta pedagógica, principalmente em relação à avaliação no EAPP, por todos os docentes e estudantes, visto que é só permitindo o erro que aprenderemos.

Percebe-se que a concepção do docente na avaliação no EAPP aproxima-se muito da abordagem de competência dialógica, em que é possível articular e integrar resultados, atributos e contexto em situações distintas, com diferentes formas de realizar tarefas essenciais para a formação do enfermeiro, ainda que contradições no processo avaliativo entre os professores estejam presentes e necessitam ser constantemente trabalhadas.

Nesse projeto político pedagógico, a avaliação no EAPP, tem tido um espaço privilegiado, ou seja, de reconstrução da prática profissional, em que se faz presente a criatividade, a sensibilidade e a disponibilidade dos estudantes e dos professores para buscar a construção dos sujeitos que possam intervir numa dada realidade com possibilidades de transformações. 
Referências

ABRECHT, R. Em que consiste a avaliação formativa? In: A avaliação formativa. Rio Tinto: Asa Editores, 1994. p. 31-61.

BARDIN, L. Análise de conteúdo. Lisboa: Edições 70, 1995.

BRASIL. Ministério da Saúde. Portaria n. 198/GM/MS de 13 de fevereiro de 2004: institui a Política Nacional de Educação Permanente em Saúde como estratégia do Sistema Único de Saúde para formação e o desenvolvimento de trabalhadores para o setor e da outras providências. Brasília, 2004. Disponível em: http://www2.prefeitura.sp.gov.br/. secretarias/saude/legislacao/0137. Acesso em: 14 jul. 2006.

DAVINE, M. C. Currículo integrado. In: BRASIL. Ministério da Saúde. Secretaria Geral. Secretaria de Modernização Administrativa e Recursos Humanos. Capacitação pedagógica para instrutor/supervisor: área da saúde. Brasília, 1989. p. 39-55.

DELUIZ, N. Qualificação, competências e certificação: visão do mundo do trabalho. Formação, Brasília, v. 1, n.2, p. 5-15, maio 2001.

DESPREBITERIS L. O desafio da avaliação da aprendizagem: dos fundamentos a uma proposta inovadora. São Paulo: EPU, 1989.

FACULDADE DE MEDICINA DE MARILIA. Programa de Incentivo a Mudanças Curriculares no Cursos de Medicina - PROMED: Faculdade de Medicina de Marília - FAMEMA: uma nova escola médica para um novo sistema de saúde: projeto final da FAMEMA. Marilia, 2003. Disponível em: $<$ http://www.famema.br/documentos/promed_final.pdf $>$. Acesso em: 23 abr. 2007.

FACULDADE DE MEDICINA DE MARILIA. Programa Nacional de Reorientação da Formação Profissional em Saúde - PRO-SAÚDE: Faculdade de Medicina de Marília - FAMEMA: FAMEMA em novas perspectivas: Curso de Enfermagem. Marilia, 2005. Disponível em: http://www.famema.br/documentos/Prosaude_Enfermagem_Famema.pdf. Acesso em: 23 abr. 2007.

FACULDADE DE MEDICINA DE MARÍLIA. Manual de avaliação: Cursos de Medicina e Enfermagem. Marília, 2005.

FACULDADE DE MEDICINA DE MARÍLIA. Manual da Unidade de Prática Profissional: UPP4: Curso de Enfermagem, 2007. 
GOMES, R. A análise de dados em pesquisa qualitativa. In: Minayo MCS, organizadora. Pesquisa social: teoria, método e criatividade. Petrópolis: Editora Vozes; 2002. p. 67-80.

LIMA, V. V. Avaliação de competência nos cursos médicos. In: MARINS, J. J. N. et al. (Org.). Educação médica em transformação: instrumentos para a construção de novas realidades. São Paulo: HUCITEC, 2004. cap. 6, p. 123140. (Saúde em debate; 158).

LUCKESI, C. C. Verificação ou avaliação: o que pratica a escola? In:

Avaliação da aprendizagem escolar. São Paulo: Cortez, 1996. p 85-101.

MINAYO, M. C. de S. O desafio do conhecimento: pesquisa qualitativa em saúde. São Paulo/Rio de Janeiro: HUCITEC/ABRASCO,1994.

PENNA FIRME, T. Avaliação: tendências e tendenciosidade. Revista Ensaio, Rio de Janeiro, v. 1, n. 2, p. 105-115, jan./mar. 1994.

PERRENOUD, P. Avaliação: da excelência à regulação das aprendizagens entre duas lógicas. Porto Alegre: Artmed, 1999.

RAMOS, M. N. A pedagogia das competências: autonomia ou adaptação? São Paulo: Cortez, 2001.

ROLDÃO, M. C. Para um currículo do pensar e do agir: as competências enquanto referencial de ensino e aprendizagem no ensino superior. Aveiro: Universidade de Aveiro, 2005. Trabalho apresentado no Workshop Competência e Avaliação em outubro de 2005. Disponível em: http://www.uc.pt/pessoal/abade/bolonha/docs/Competencias_roldao.pdf. Acesso em: 23 abr. 2007.

SANTOMÉ, J.T. Globalização e interdisciplinaridade : o currículo integrado. Porto Alegre: Artes Médicas, 1998.

ZARIFIAN, P. A gestão da e pela competência. Rio de Janeiro: Centro Internacional para Educação, Trabalho e Transferência de Tecnologia, 1996. 